\title{
A new method of reconstructing the $P-T$ conditions of fluid circulation in an accretionary prism (Shimanto, Japan) from microthermometry of methane-bearing aqueous inclusions
}

Hugues Raimbourg ${ }^{\mathrm{a}, \mathrm{b}, *}$, Régis Thiéry $^{\mathrm{c}}$, Maxime Vacelet ${ }^{\mathrm{d}}$, Claire Ramboz ${ }^{\mathrm{a}}$, Nicolas Cluzel $^{c}$, Emmanuel Le Trong ${ }^{a}$, Asuka Yamaguchi ${ }^{\mathrm{e}}$, Gaku Kimura ${ }^{\mathrm{e}}$

${ }^{a}$ Univ. d'Orléans, ISTO, UMR 7327, 45071, Orléans, France ; CNRS, ISTO, UMR 7327, 45071 Orléans, France ; BRGM, ISTO, UMR 7327, BP 36009, 45060 Orléans, France

${ }^{b}$ IFREE, Japan Agency for Marine-Earth Science and Technology, 2-15 Natsushima-cho, Yokosuka, Kanagawa 237-0061, Japan

${ }^{c}$ LMV, Laboratoire Magmas et Volcans, UMR 6524, CNRS/Clermont Université, Clermont-Ferrand, France

${ }^{d}$ MINES-Paristech, Centre de Géosciences, 35, rue Saint-Honoré, r7305 Fontainebleau Cedex, France

${ }^{e}$ Department of Earth and Planetary Science, The University of Tokyo, 7-3-1 Hongo, Bunkyo-ku, Tokyo 113-0033, Japan

\section{Abstract}

In paleo-accretionary prisms and the shallow metamorphic domains of orogens, circulating fluids trapped in inclusions are commonly composed of a mixture of salt water and methane, producing two types of fluid inclusions: methane-bearing aqueous and methane-rich gaseous fluid inclusions. In such geological settings, where multiple stages of deformation, veining and fluid influx are prevalent, textural relationships between aqueous and gaseous inclusions are often ambiguous, preventing the microthermometric

\footnotetext{
* Corresponding author

Email addresses: hugues.raimbourg@univ-orleans.fr (Hugues Raimbourg), r.thiery@opgc.univ-bpclermont.fr (Régis Thiéry)
} 
determination of fluid trapping pressure and temperature conditions.

To assess the $P-T$ conditions of deep circulating fluids from the Hyuga unit of the Shimanto paleo-accretionary prism on Kyushu, Japan, we have developed a new computational code, applicable to the $\mathrm{H}_{2} \mathrm{O}-\mathrm{CH}_{4}-\mathrm{NaCl}$ system, which allows the characterization of $\mathrm{CH}_{4}$-bearing aqueous inclusions using only the temperatures of their phase transitions estimated by microthermometry: $T_{m \mathrm{i}}$, the melting temperature of ice; $T_{\mathrm{hyd}}$, the melting temperature of gas hydrate and $T_{h \text {,aq }}$, homogenization temperature. This thermodynamic modeling calculates the bulk density and composition of aqueous inclusions, as well as their $P-T$ isochoric paths in a $P-T$ diagram with an estimated precision of approximatively $10 \%$.

We use this computational tool to reconstruct the entrapment $P-T$ conditions of aqueous inclusions in the Hyuga unit, and we show that these aqueous inclusions cannot be cogenetic with methane gaseous inclusions present in the same rocks. As a result, we propose that pulses of a high-pressure, methanerich fluid transiently percolated through a rock wetted by a lower-pressure aqueous fluid. By coupling microthermometric results with petrological data, we infer that the exhumation of the Hyuga unit from the peak metamorphic conditions was nearly isothermal and ended up under a very hot geothermal gradient.

In subduction or collision zones, modeling aqueous fluid inclusions in the ternary $\mathrm{H}_{2} \mathrm{O}-\mathrm{CH}_{4}-\mathrm{NaCl}$ system and not simply in the binary $\mathrm{H}_{2} \mathrm{O}-\mathrm{NaCl}$ is necessary, as the addition of even a small amount of methane to the water raises significantly the isochores to higher pressures. Our new code provides therefore the possibility to estimate precisely the pressure conditions of fluids 
circulating at depth.

Keywords: fluid inclusions, microthermometry, Raman spectroscopy, gas hydrates, $\mathrm{H}_{2} \mathrm{O}-\mathrm{CH}_{4}-\mathrm{NaCl}$

\section{Introduction}

2

Using observation of thousands of fluid inclusions in quartz veins from the Central Alps, Mullis (1979) and Mullis et al. (1994) recognized the correspondence of the nature of the fluid with metamorphic grade: Methane-bearing aqueous fluids are dominant at low metamorphic grade, up to $\sim 300^{\circ}$ C. Similarly, water and methane have been identified as the major components of the fluid in many worldwide paleo-accretionary prisms, including the Shimanto Belt in Japan (Sakaguchi, 1999a; Lewis et al., 2000; Kondo et al., 2005), Kodiak Island in Alaska (Vrolijk et al., 1988) and the Franciscan Complex in California (Dalla Torre et al., 1996; Sadofsky and Bebout, 2004). Fluid inclusions carry invaluable information regarding pressure $(P)$ - temperature $(T)$ conditions of the fluid at the time of trapping and, indirectly, of the host terrane, in the shallow portion $(P \sim 0-500 \mathrm{MPa})$ of subduction and collision zones where the analysis of complex phase assemblages with the help of thermodynamic databases and software (e.g. THERMOCALC, (Powell and Holland, 1988) or TWEEQU (Berman, 1991)) is not possible.

To this end, the following procedure (e.g. Alderton and Bevins, 1996), which is applicable when aqueous inclusions and methane-rich gaseous inclusions are simultaneously present, is commonly used (see Table 1 for a list of symbols): If one assumes that these inclusions were trapped under the same conditions, then the trapping pressure $\left(P_{t}\right)$ and temperature $\left(T_{t}\right)$ can 
be estimated on a $P-T$ diagram from the intersection of the isochores of gaseous inclusions with the isotherm $T=T_{h, \mathrm{aq}}$ of aqueous inclusions (where $T_{h \text {,aq }}$ is the homogenization temperature of aqueous inclusions). The central assumption of this method is that the two types of fluid inclusions derive from the entrapment of the two end-members of an immiscible mixture of a $\mathrm{CH}_{4}\left( \pm \mathrm{H}_{2} \mathrm{O}\right)$ gas in equilibrium with a dense $\mathrm{H}_{2} \mathrm{O}-\mathrm{NaCl}\left( \pm \mathrm{CH}_{4}\right)$ solution. In other words, this method assumes that aqueous and gaseous inclusions are cogenetic.

This assumption is commonly based on the distribution and the geometry of the inclusions (e.g. primary inclusions of the two kinds trapped in the same crystal). However, in orogenic settings, where rocks have experienced multiple stages of deformation and fluid influx, most inclusions are secondary and textures are often ambiguous.

Thus, one must assess if there was a single fluid at depth or if the two kinds of inclusions correspond to two unrelated fluids, trapped at either the same or even different $P-T$ conditions. To this end, an approach alternative to texture analysis is to determine, from microthermometric measurements, the possibility for several populations of fluid inclusions to be thermodynamically in equilibrium (Pichavant et al., 1982; Ramboz et al., 1982). To prove their cogenetic character, several conditions must be met, including a similar temperature for total homogenization. This transition is readily observable in water-rich fluid inclusions by the disappearance of thermally agitated bubbles of methane. In methane-rich inclusions, the water phase, occupying a low volume fraction and forming a meniscus on the rim of the inclusion, is often not visible, hence total homogenization cannot be mea- 
sured optically. An alternative solution was developed by Mullis (1979), who showed good agreement between the estimated molar fraction of methane in water-rich inclusions and the saturation concentration of methane in water for the $P-T$ conditions of equilibrium between water-rich and methane-rich fluid inclusions. This method is nevertheless restricted to exceptionnally large water-rich fluid inclusions where the density of the bubble of methane can be estimated with a freezing stage. In general, however, it is often difficult to check the cogenetic character of methane-rich and water-rich inclusions. The above mentioned difficulties present themselves when working with aqueous $\mathrm{H}_{2} \mathrm{O}-\mathrm{NaCl}-\mathrm{CH}_{4}$ inclusions in rocks of the Shimanto paleo-accretionary complex (Japan). In particular, small $(\sim 5 \mu m)$, aqueous inclusions are associated with some gaseous $\mathrm{CH}_{4}$ inclusions, whose cogenetic character cannot be clearly supported by texture analysis. Unfortunately, such ambiguous textural relationships are common in orogenic contexts, limiting the scope of microthermometry in these formations.

Regardless, aqueous inclusions exhibit one additional phase transition, which is the melting of a gas hydrate in the presence of a vapour phase. Its temperature can be measured by microthermometry, generally between $0^{\circ} \mathrm{C}$ and $15^{\circ} \mathrm{C}$, and this data gives us one additional constraint to characterize aqueous inclusions in terms of bulk content and density. Two models to this end (Dubessy et al., 1992; Mao et al., 2011) already exist in the literature, but none can be applied to Shimanto paleo-accretionary complex: Dubessy et al. (1992) does not take into account $T_{h, \text { aq }}$, whereas Mao et al. (2011) does not take into account the presence of dissolved salts. We have, therefore, built a new algorithm allowing the complete characterization of the 
properties of an aqueous $\mathrm{CH}_{4}$ and $\mathrm{NaCl}$-bearing aqueous inclusion (i.e. bulk density, bulk content, isochoric paths) using three measured phase transition temperatures: $T_{m \mathrm{i}}$, melting temperature of ice; $T_{\text {hyd }}$, melting temperature of gas hydrate and $T_{h \text {,aq }}$, homogenization temperature. This new model is described in Section 4 after a discussion of the geological context (Section 2) and of the microthermometric analysis (Section 3).

Section 6 synthesizes the main results, which have been obtained from this microthermometric work and thermodynamic modeling and shows that the Hyuga unit has experienced important fluid composition changes in the past (methane-rich and water-rich fluids in disequilibrium) as well as variations in thermal regime.

\section{Geological context}

The Hyuga Group is part of the Shimanto Belt on Kyushu, Japan (Fig. 1). This belt is interpreted as a paleo-accretionary complex formed during the subduction of the Pacific plate below the Eurasian Plate (Taira et al., 1988). It is divided by the Nobeoka Tectonic Line (NTL), an out-ofsequence megathrust, several hundreds of kilometers long, marking a large stratigraphic and metamorphic gap (Imai et al., 1971; Toriumi and Teruya, 1988).

The Hyuga mélange is the uppermost unit of the Hyuga Group and constitutes the footwall of the NTL. It was strongly deformed and affected by metamorphism, with peak temperature conditions estimated around $250-300^{\circ} \mathrm{C}$ on the basis of vitrinite reflectance (Kondo et al., 2005) or illite cristallinity (Hara and Kimura, 2008; Mukoyoshi et al., 2009). In addition, Mukoyoshi 
et al. (2009) describe a lateral temperature gradient from the east $\left(\sim 250^{\circ} \mathrm{C}\right)$ to the west $\left(\sim 280^{\circ} \mathrm{C}\right)$. Furthermore, based on prehnite-pumpellyite metamorphic assemblages in greenstones included in the mélange, Toriumi and Teruya (1988) estimated the peak metamorphic conditions as 3-5 kbars and $200-300^{\circ} \mathrm{C}$.

The Hyuga mélange has a block-and-matrix structure, where blocks are made of lenses of sandstone/siltstone or early stage quartz veins and matrix is rich in phyllosilicates. The ductile deformation, associated with peak metamorphic conditions, is pervasive and apparent in (1) the foliation, defined both from the elongated shape of the blocks and the preferential orientation of the phyllosilicates in the matrix, (2) top-to-SE shear zones in the matrix and (3) stretching/necking of the blocks. At the grain scale, ductilely deformed quartz grains are preferentially elongated parallel to the foliation and show undulose extinction, subgrains and bulging grain boundaries (Fig. 2A_2). Note that the plastic deformation of quartz is more apparent in the west of the Hyuga mélange unit, in agreement with the slightly higher metamorphic conditions, than along the eastern coast, which somehow explains why it is not described in Kondo et al. (2005).

The mélange rocks have been pervasively affected by quartz veining throughout their history. We define early-stage veins as those containing quartz grains that have been plastically deformed and late-stage veins as those crosscutting the ductile deformation microstructures and containing grains devoid of plastic deformation. The latter veins are preferentially orientated perpendicular to the foliation and are often restricted to the blocks of the mélange, i.e. not propagating into the phyllosilicate-rich matrix. 
All the quartz grains in veins contain fluid inclusions, most often with a very high density (Fig. 2). As plastic deformation of host quartz grains can potentially affect their volume, fluid inclusions predating or synchronous with the ductile phase cannot be studied by microthermometric methods, which assume an isochoric evolution of the inclusions from their trapping. Our study is thus necessarily restricted to late-stage quartz veins, devoid of plastic deformation (Fig. 2A and B).

In the Hyuga mélange (Fig. 1), Kondo et al. (2005) described two kinds of fluid inclusions in quartz veins: aqueous inclusions and gaseous $\mathrm{CH}_{4}$-bearing inclusions (Fig. 3). Assuming that these inclusions were cogenetic, Kondo et al. (2005) could derive the minimum $P_{t}$ and $T_{t}$ conditions of trapping from the intersection of the isochore of $\mathrm{CH}_{4}$ inclusions with the $T_{h \text {,aq }}$ isotherm (e.g. Mullis, 1979).

Our own analysis (microthermometry and Raman microspectrometry) of samples of Kondo et al. (2005) confirmed the presence of aqueous and gaseous $\mathrm{CH}_{4}$-rich inclusions. All these inclusions, distributed within late-stage veins, have very irregular shapes (Fig. 2A_3 and B_3). In some cases, they are clearly organized as planes of inclusions (Fig. 2B_3), i.e. they are secondary inclusions; in other cases their nature is obscure. The cogenetic nature of these two kinds of inclusions, if possible, is questionable in two respects:

1. There is no textural evidence, apart from their presence in the same crystals, to the fact that water-rich and methane-rich fluid inclusions were trapped together and are thus representative of the two endmembers of coexisting liquid and vapour fluid phases. In particular, the gaseous $\mathrm{CH}_{4}$-rich inclusions are all contained within fracture planes 
that do not contain any aqueous inclusion. We found neither primary fluid inclusions of the two kinds in the same crystal or secondary inclusions of the two kinds in the same fracture plane.

2. Using a more extensive sampling of the Hyuga unit than Kondo et al. (2005), we discovered that gaseous $\mathrm{CH}_{4}$-rich inclusions are restricted, in fact, to the easternmost side, while water-rich fluid inclusions are distributed throughout the whole unit (blue dots in Fig. 1). Thus, the presence of $\mathrm{CH}_{4}$-rich inclusions appears rather as a peculiarity, and aqueous fluids are not necessarily considered to be at equilibrium with a $\mathrm{CH}_{4}$-rich phase and thus to represent the liquid aqueous end-member saturated with respect to a vapour $\mathrm{CH}_{4}$-rich phase.

As a consequence, these preliminary observations lead us to question the effective circulation of mixtures of methane-saturated waters and $\mathrm{CH}_{4}$ gas during the trapping of fluid inclusions.

\section{Microthermometry}

\subsection{Apparatus}

The selected quartz fragments were placed on a $200 \mu \mathrm{m}$-thick, $1.6 \mathrm{~cm}$-wide rounded glass window on top of the silver block of the THMS-600 Linkam heating-cooling stage. Phase changes in the inclusions were observed using an Olympus BHS microscope equipped with a $\times 80$ ULWD Olympus objective and recorded by a Marlin black and white camera (CMOS 2/3" sensor, resolution $1280 \times 1024$ pixels, pixel size of $6.7 \mu \mathrm{m})$. Temperature was measured using a class B Pt 100 thermistance, which has an intrinsic precision of $0.15^{\circ}$ to $1.35^{\circ} \mathrm{C}$ between $0^{\circ}$ and $600^{\circ} \mathrm{C}$. Temperature is sampled every $\sim 300 \mathrm{~ms}$ by 
a Eurotherm 902 controller which allows analogic output. The temperature cycles of the stage (heating - cooling rate and temperature steps) are controlled using a LabVIEW@ computer program. In the vicinity of the phase transitions, we chose slow heating rates about $\sim 1^{\circ} \mathrm{C} / \mathrm{min}$.

The stage was calibrated according to the procedure detailed in El MekkiAzouzi (2010) between $-56.6^{\circ} \mathrm{C}$ and $573^{\circ} \mathrm{C}$ against 8 reference temperatures. The standards used were:

1. either natural and synthetic fluid inclusions: melting point of $\mathrm{CO}_{2}$ at $-56.6^{\circ} \mathrm{C}$, melting point of ice : $0^{\circ} \mathrm{C}$,

2. or ceramics: solid - solid transitions at $37^{\circ} \mathrm{C}$ and $47^{\circ} \mathrm{C}$ in $\mathrm{CsPbCl}_{3}$ and at $180^{\circ} \mathrm{C}$ in $\mathrm{Pb}_{3}\left(\mathrm{PO}_{4}\right)_{2}$,

3. or salts $: b / g \rightarrow a$ transition at $147^{\circ} \mathrm{C}$ in $\mathrm{AgI}$ and subsequent melting at $557^{\circ} \mathrm{C}$,

4. or minerals : $a \rightarrow b$ transition in quartz at $573^{\circ} \mathrm{C}$.

Based on the calibration, the temperature accuracy is around $\pm 1^{\circ} \mathrm{C}$ over the whole investigation temperature range, from $-120^{\circ} \mathrm{C}$ to $+290^{\circ} \mathrm{C}$, but much better, of the order of $\pm 0.1^{\circ} \mathrm{C}$ in the temperature range from $-10^{\circ}$ to $+20^{\circ} \mathrm{C}$, where ice and gas hydrate melting occurs.

\subsection{Gaseous methane-rich fluid inclusions}

These inclusions are restricted to the easternmost, coastal side of the Hyuga unit. They are monophasic at ambient temperature. Upon cooling, they nucleate a bubble below $-82.7^{\circ} \mathrm{C}$ (the critical temperature of pure methane) and thus, we measured these homogenization temperatures $\left(T_{h}\right)$ to liquid. $T_{h}$ distribution is roughly unimodal, with a principal peak between 
$-115^{\circ} \mathrm{C}$ and $-105^{\circ} \mathrm{C}$ (Fig. 4), similar to what was described in Kondo et al. (2005).

\subsection{Aqueous fluid inclusions}

Water-rich fluid inclusions were collected in the whole Hyuga unit (Fig. 1), including the eastern sides, where methane-rich inclusions are also present. At ambient temperature, they are biphasic, with a methane-rich bubble of vapor embedded in a water-rich liquid (Fig. 3). Upon heating, the size of the methane vapor bubble is progressively reduced, up to its complete dissolution in the liquid phase at the homogenization temperature $\left(T_{h, \text { aq }}\right)$. In the final steps of heating, when the bubble has sufficiently shrinked, it is systematically affected by thermal agitation. The bubble rapid movement can be easily observed, even in very small (below $5 \mu \mathrm{m}$ ) inclusions, so that $T_{h, \text { aq }}$ estimation can be carried out efficiently on a large pool of inclusions of various size and shape. Homogenization temperatures are reproducible with a precision of $\sim 1^{\circ} \mathrm{C}$. In the inclusions where all phase transitions were observable (Tab. 2), $T_{h, \text { aq }}$ range from 200 to $280^{\circ} \mathrm{C}$, i.e. similar to measurements by Kondo et al. (2005).

On the other hand, the measurements of the temperatures of ice melting $\left(T_{m \mathrm{i}}\right)$ and gas hydrate disappearance $\left(T_{\mathrm{hyd}}\right)$ are more difficult to carry out. In theory, $T_{m \mathrm{i}}$ and $T_{\text {hyd }}$ can be estimated, during heating, by visual observation of the disappearance of ice and gas hydrate, respectively. However, in practice, the inclusions are either too small or too crowded, so that the ice and and gas hydrate crystals are not visible. Fortunately, their presence, at the interface between the liquid and the vapor bubble, can be indirectly detected by their influence on the bubble shape, size or position within the 
inclusion. As a consequence, we restricted the complete microthermometric observations to the largest fluid inclusions, and we had to apply a specific procedure of cyclic heating and cooling (Ramboz, 1980) to measure $T_{m \mathrm{i}}$ and $T_{\text {hyd }}$.

The method of Ramboz (1980) is based on successive cycles of heating and cooling, which allow to determine the temperature of disappearance of ice/gas hydrate. It can be described as follows (Fig. 5 and movies in Supplementary Material):

1. First, freeze the inclusion up to formation of ice/gas hydrate.

2. Heat slowly the inclusion to melt progressively the ice/gas hydrate, up to a given temperature (let's say $T_{i}$ for the cycle \#i).

3. Then freeze very rapidly the inclusion and observe possible variations in its size, shape of location.

4. Repeat steps (2) and (3) for increasing $T_{i}$ temperatures, until for some $T_{n}$, rapid freezing has no effect on the vapour bubble (no shrinkage and no deformation). This indicates that ice/gas hydrate seeds have completely disappeared.

The melting temperature $\left(T_{m}\right.$, i.e either $T_{m \mathrm{i}}$ or $\left.T_{\text {hyd }}\right)$ of ice/gas hydrate is then approximated by $T_{n-1}<T_{m}<T_{n}$. The precision depends on the temperature increments, and it can be set up to the precision of the microthermometric equipment (i.e. a precision of $0.1^{\circ} \mathrm{C}$ ).

In practice, for ice, initial freezing was done at a temperature around -35 to $-40^{\circ} \mathrm{C}$ (step 1), where ice filled instantaneously the inclusion. For gas hydrate, the temperature of initial freezing was above $T_{m i}$, i.e. at a state where the fluid inclusion contains three phases (gas hydrate, aqueous solution 
and gas bubble).

For ice, the measurement of $T_{m \mathrm{i}}$ is systematically reproducible within \pm $0.1^{\circ} \mathrm{C}$, as the bubble shrinkage caused by ice formation is easily detectable. However, for gas hydrates, the procedure is much less efficient. As the bulk content of $\mathrm{CH}_{4}$ is very low, the volumetric proportion of gas hydrate is also very low. Thus, its growth does not affect much the gas bubble, and its effect is only detectable in favourable cases, when the gas hydrate deforms the shape of the vapor bubble or changes its position in the inclusion. Hence, only a fraction of the inclusions showed some response to freezing/heating cycles. Moreover, in some of these inclusions, it was noted that the measurements of $T_{\text {hyd }}$ were not reproducible after a complete freezing below $\sim-40^{\circ} \mathrm{C}$. We postulate that the reason is a change in the position of the gas hydrate crystal seed, but had to discard the results of these inclusions.

Table 2 gives the complete data set $\left(T_{m \mathrm{i}}, T_{\text {hyd }}\right.$ and $\left.T_{h, \text { aq }}\right)$ measured for seven aqueous inclusions. Homogenization temperatures $T_{h \text {,aq }}$ range from $\sim$ $200^{\circ}$ to $280^{\circ} \mathrm{C}$. On the other hand, $T_{m \mathrm{i}}$ and $T_{\mathrm{hyd}}$ are restricted to relatively narrow ranges, from $-3.15^{\circ}$ to $-1.9^{\circ} \mathrm{C}$ and from $5.3^{\circ}$ to $10.4^{\circ} \mathrm{C}$, respectively.

\section{Thermodynamic modeling of aqueous inclusions}

The fluid inclusions of this study can be ascribed to the $\mathrm{H}_{2} \mathrm{O}-\mathrm{CH}_{4}-\mathrm{NaCl}$ system. Thus, if they contain sufficient $\mathrm{CH}_{4}$, they undergo the following phase transitions from low to high temperatures (Bakker, 1997; Bakker and Thiéry, 1994):

- first (state 1), melting of the last ice crystal in the presence of a gas hydrate $(\mathrm{H})$, an aqueous solution $\left(\mathrm{L}_{w}\right)$ and a gas bubble $(\mathrm{G})$ at a tem- 
perature $T_{1}=T_{m \mathrm{i}}$,

- then (state 2), melting of the last gas hydrate crystal in the presence of an aqueous solution and a gas bubble at a temperature $T_{2}=T_{\text {hyd }}$,

- and eventually (state 3), diasppearance of the gas bubble (homogenization point) at a temperature $T_{3}=T_{h, \text { aq }}$.

To our knowledge, at least two thermodynamic models (Dubessy et al., 1992; Mao et al., 2011) have been devised to characterize such fluid inclusions exhibiting gas hydrates. However, none of them can be applied to the present study: the model of Dubessy et al. (1992) does not make use of homogenization temperatures and the model of Mao et al. (2011) does not allow for the presence of $\mathrm{NaCl}$. Therefore, specific thermodynamic modeling has to be developed to interpret our microthermometric data. The method proposed here is an extension of the model of Dubessy et al. (1992), which has been associated to a $\mathrm{CH}_{4}$ solubility model (e.g. Duan and Mao, 2006) for NaCl-bearing aqueous solutions.

Our algorithm is based on the assumption that fluid inclusions behave as closed and isochoric systems. Thus, the key equations can be given by the following set of expressions:

$$
\left\{\begin{aligned}
n_{\mathrm{H}_{2} \mathrm{O}, 1} & =n_{\mathrm{H}_{2} \mathrm{O}, 2} \\
n_{\mathrm{CH}_{4}, 1} & =n_{\mathrm{CH}_{4}, 2} \\
n_{\mathrm{NaCl}, 1} & =n_{\mathrm{NaCl}, 2} \\
\rho_{2} & =\rho_{3}
\end{aligned}\right.
$$


where the meaning of the symbols used here (and in all what follows) is given in Table 1 . The volume conservation between states 1 and 2 , and between states 2 and 3, as well, is implicitly expressed in these equations. The first three equations express the mass balance of, respectively, $\mathrm{H}_{2} \mathrm{O}, \mathrm{CH}_{4}$ and $\mathrm{NaCl}$, between state 1 (ice melting) and state 2 (gas hydrate melting) in a fluid inclusion of $1 \mathrm{~m}^{3}$ of volume. The last equation formulates the mass conservation between state 2 and state 3 (homogenization).

As a consequence, this set of four equations represents a closed form of the constraints (volume and matter conservation) imposed on a fluid inclusion in the $\mathrm{H}_{2} \mathrm{O}-\mathrm{CH}_{4}-\mathrm{NaCl}$ system. These equations are further developed in Appendix A. Other thermodynamic quantities do not explicitly appear in the equations above, but are implicitly required. In particular, this is the case of pressures of gas hydrate dissociation $\left(P_{1}\right.$ and $\left.P_{2}\right)$, which are calculated by a thermodynamic model describing gas hydrate melting (e.g. Munck et al., 1988). $\mathrm{NaCl}$ activities in aqueous solutions are also needed and are calculated by a model for activity coefficients of dissolved salts (Pitzer, 1973). Molar volumes $\left(V^{G}\right)$ of the gas phase are calculated by the equation of state of Soave (1972). Additional details are given in Dubessy et al. (1992).

At the end, in the whole set of equations (1), it appears that there are only four unknowns: $F_{1}^{L_{w}}$, the volume proportion of the aqueous liquid at state $1 ; F_{1}^{H}$, the volume proportion of gas hydrate at state $1 ; F_{2}^{L_{w}}$, the volume proportion of aqueous solution at state 2 ; and $m_{\mathrm{NaCl}, 2}$, the $\mathrm{NaCl}$ molality in the aqueous solution at state 2. Thus, with four unknowns for four equations, the problem is completely solvable. Only one solution is found by using an iterative Newton algorithm for a given set of microthermometric 
measurements $\left(T_{m \mathrm{i}}, T_{\text {hyd }}\right.$ and $\left.T_{h, \text { aq }}\right)$. Therefore, the present procedure represents an interesting enhancement of the method of Dubessy et al. (1992), which could not fully characterize the bulk properties of the fluid inclusion without relying upon the imprecise estimation of the bubble filling degree $F_{2}^{G}$ at $T_{2}$.

One discussion point is concerned with the error propagation produced by the successive equations of state used in our calculations. From the literature indications, the solubility models deviate at most by around $6 \%$ from experimental data (Duan and Mao, 2006; Spivey et al., 2004). Density models for $\mathrm{H}_{2} \mathrm{O}-\mathrm{NaCl}$ solutions are more accurate with deviations within $1 \%$ (Spivey et al., 2004; Duan and Mao, 2006). We have tested different combinations of thermodynamic models (Duan and Mao, 2006; Spivey et al., 2004; Duan et al., 1992; Potter and Brown, 1977; Pitzer, 1973) and we found no deviation above $12 \%$ in the calculated methane concentration, which is well consistent with the precision degree we estimated for our calculations.

\section{Reconstitution of paleo pressures and temperatures}

\subsection{P-T-X trapping conditions of the Hyuga mélange unit}

The thermodynamic modeling described in the preceding section has been applied to analyse the microthermometric data obtained on fluid inclusions from the Hyuga unit. Computed salinities and bulk methane concentrations are given in Table 2. Both show large relative variations, even within samples collected in the same area, either in the west (HN48, HN51 and HN87) or on eastern coast (Kon-NB26). $\mathrm{CH}_{4}$ concentrations are positively correlated with homogenization temperatures, reflecting the fact that solubility at high 
$P$ and $T$ is mostly controlled by the temperature (Duan and Mao, 2006). Salinities are systematically below oceanic levels.

Monophasic isochores of gaseous inclusions, calculated from the web page http://webbook.nist.gov/chemistry/fluid/ from the National Institute of Standards and Technology using the equation of state by Setzmann and Wagner (1991) and biphasic liquid-gas isochores of aqueous inclusions, calculated using Duan and Mao (2006), are plotted in Fig. 6. From this diagram, one important conclusion emerges: isochores of gaseous inclusions do not intersect biphasic isochores of aqueous inclusions. They run even at much higher pressures than homogenization pressures of aqueous inclusions. Thus, aqueous and gaseous inclusions cannot be cogenetic.

As a consequence, the inclusions have registered, at least, two types of fluid circulations with marked composition differences: one involving dense aqueous solutions with some minor dissolved methane, and another one composed of light methane-rich gas. Methane pulses have probably occured at larger pressures than aqueous solutions, but at this stage, other arguments must be searched to constrain further the trapping pressures and temperatures of these fluids.

The problem can be partially solved by considering the rock maximum temperature $\left(T_{\max }\right)$, as recorded by the vitrinite reflectance (Kondo et al., 2005) or the illite cristallinity (Hara and Kimura, 2008; Mukoyoshi et al., 2009). Here, $T_{\max }$ is of the order of $250-280^{\circ} \mathrm{C} \pm 30^{\circ} \mathrm{C}$, i.e. a temperature range in line with the highest of $T_{h, \text { aq }}$ values (Fig. 6 and Tab. 2).

It is always possible that circulating fluids were significantly hotter than the host rock, but were not abundant enough to influence the bulk rock tem- 
perature (i.e. $T_{t}>T_{\max }$ ). However, a large temperature discrepancy between $T_{t}$ and $T_{\max }$ is unlikely, as the rocks considered here are pervasively filled by quartz veins, corresponding originally to circulating fluids. Furthermore, in the case of a large $T_{t}-T_{\max }$ disequilibrium, fluids would be trapped at various temperatures ranging from $T_{\max }$ (for small fluid pulses, locally buffered by the bulk rock temperature) up to the fluid source temperature (for larger fluid pulses, not buffered). Consequently, we should expect a broad distribution for trapping temperatures $T_{t}$ in this case.

However, Fig. 6 suggests a simpler solution. Indeed, it is striking that the bulk rock peak temperatures $\left(T_{\max }\right)$ are roughly of the same magnitude as:

1. either $T_{h, \text { aq }}$ temperatures of aqueous inclusions (inclusions: Kon-NB26ech27 inclusion 26, HN51-4c, HN48b-inc a and inc b, HN87-inc c). In this case, $T_{t}=T_{h, \text { aq }}$ and $P_{t}=P_{h \text {,aq }}$. Most of the aqueous inclusions have recorded these $P_{t}-T_{t}$ conditions.

2. or temperatures of intersection points between monophasic isochores of aqueous and gaseous inclusions (inclusions: Kon-NB26-ech27 inclusions 27 and 30). In this case, $T_{t}=T_{\max }$ and $P_{t}=P_{\mathrm{aq}}\left(T_{t}\right)=P_{g}\left(T_{t}\right)$ (where $P_{g}$ is the pressure of gasous inclusions along their monophasic isochores). Both aqueous and gaseous inclusions have recorded these $P_{t}-T_{t}$ conditions, but, as aqueous fluid inclusions are undersaturated in methane (as they are in the single-phase domain, see Fig. 6), they are not at equilibrium with gaseous inclusions. In other words, two fluids penetrated the rock for these $P-T$ conditions, but they were not at equilibrium with each other, hence not cogenetic. This case is an 
illustration of the conditions to be fulfilled for two fluids to be at equilibrium, as developed in Ramboz et al. (1982): they must not only share the same $P$ and $T$ but also, in terms of composition, be exactly on the immiscibility surface between a methane-rich and a water-rich fluid. This latter condition can also be expressed as that the common $P-T$ conditions must coincide with the saturation in methane for the aqueous inclusion.

In conclusion, we think that trapping occurred:

1. for roughly constant temperatures $T_{t} \sim T_{\max }$ with fluids in thermal equilibrium with hosting rocks at temperatures between 250 and $280^{\circ} \mathrm{C}$,

2. but in a retrometamorphic context featured by a large decrease in fluid pressure, from 250 to $50 \mathrm{MPa}$.

Furthermore, in both cases exposed above, aqueous fluids appear to be methane-undersaturated at their $\left(P_{t}, T_{t}\right)$ trapping conditions, i.e. water-rich and methane-rich fluids, even when trapped for similar P-T conditions, are not at equilibrium with each other. Thus, during exhumation, we should not imagine the rock as being soaked by a single fluid mixture, but rather transiently percolated by pulses of higher-pressure, methane-rich fluids coming from the depth and in chemical disequilibrium with the local, lower-pressure aqueous fluid, undersaturated in methane.

\subsection{Geothermal evolution of the unit of the Hyuga melange unit}

The trapping conditions inferred in the preceding section correspond to a late-stage event in the polyphased history of the rocks, as aqueous and 
gaseous inclusions are contained into late-stage veins that postdate the metamorphic assemblages formed at peak conditions. When comparing the P-T evolution from the metamorphic peak to this late-stage event, pressure decreased from 300-500 $\mathrm{MPa}$, while temperature remained in the same range (Toriumi and Teruya, 1988), in other words, Hyuga unit was exhumed along a nearly isothermal path (Fig. 6). This exhumation pattern involves a sharp change in the thermal regime, from a geothermal gradient, for peak conditions, similar to the current subduction margin of SW Japan (Oleskevich et al., 1999; Hyndman et al., 1995; Peacock, 2009) to a much higher gradient during its late-stage evolution.

To estimate precisely this late-stage geothermal gradient from fluid inclusion data, one needs to know where the fluid pressure is placed between hydrostatic and lithostatic pressure. Assuming hydrostatic fluid pressure yields a lower bound on the gradient; taking sedimentary rock volumic mass as $2.7 \mathrm{~g} / \mathrm{cm}^{3}$, the lowest fluid pressure recorded by aqueous fluid inclusions, $50 \mathrm{MPa}$ (Fig. 6), converts into a lithostatic pressure of $135 \mathrm{MPa}$, for a temperature of $\sim 250^{\circ} \mathrm{C}$. This gradient is even higher than in the Cascadia subduction zone, the "hottest" modern margin for which thermal models are available (Oleskevich et al., 1999; Peacock, 2009).

The reasons for this thermal event are not yet clear. Terranes of the Shimanto Belt on Shikoku also recorded an event of late-stage heating, with water-rich associated fluids (Sakaguchi, 1996, 1999a,b), interpreted by these authors as the result of the subduction of a paleo-ridge at Eocene time (e.g. Lewis et al. (2000)). In Hyuga mélange, the youngest stratigraphic ages of blocks embedded in the matrix are Early Oligocene (Sakai et al., 1984). The 
thermal event, which postdates the metamorphic deformation of these rocks, must therefore be significantly younger than Early Oligocene, hence cannot be explained by the Eocene paleo-ridge subduction. Another candidate is the subduction of the Shikoku Basin spreading center, on the Philippines sea plate, which was active from Early to Middle Miocene and which subducted nearly perpendicular to the margin (Letouzey and Kimura, 1985; Hall, 2002). As a result, the geothermal gradient in Middle Miocene, resulting from the subduction of an active ridge, was much higher than the modern one or the one that prevailed during the metamorphic deformation of the Hyuga mélange. Thermal models for the subduction along the SW Japan of a 15 (i.e. the actual margin), 10 and 5 Ma old crust by Hyndman et al. (1995), give for the latter, young and hot oceanic crust, results in relative agreement with the late-stage gradient recorded by the aqueous fluid inclusions. One can also note that the Middle Miocene corresponds to a stage of widespread magmatism, as evidenced by numerous granite and granodiorite intrusions along the margin (Fig. 1), which may have further contributed to heat the deep rocks of the Shimanto accretionary prism. Although precise radiometric dating are not yet available, we tentatively attribute the heating event recorded by the late-stage, aqueous inclusions analyzed here to the Middle Miocene tectonic and paleogeographic settings.

\subsection{A sensitive tool for pressure estimations in accretionary prisms}

To assess the $P-T$ conditions of fluid circulating at depth, fluid inclusions have been exploited in previous studies in accretionary prisms, like Kodiak in Alaska (Vrolijk, 1987; Vrolijk et al., 1988) or Shimanto in Japan (Lewis et al., 2000; Sakaguchi, 1999a; Kondo et al., 2005). These studies assume that 
aqueous $\mathrm{H}_{2} \mathrm{O}-\mathrm{CH}_{4}-\mathrm{NaCl}$ inclusions and gaseous $\mathrm{CH}_{4}$ inclusions are cogenetic. This hypothesis is attractive as it allows to get a first approximate of the trapping $P_{t}-T_{t}$ conditions. However, in practice, the coevality of these fluid inclusions is extremely difficult to ascertain in rocks affected by multiple stages of deformation. Thus, the assumption of cogenetic trapping is no more satisfactory. The procedure we proposed here overcomes the problem and permits to get an independent estimation of trapping pressures $P_{t}$ of aqueous $\mathrm{H}_{2} \mathrm{O}-\mathrm{CH}_{4}-\mathrm{NaCl}$ inclusions. Additionally, this method is applicable even in the absence of $\mathrm{CH}_{4}$ inclusions, as it is often the case in the Hyuga melange unit of the Shimanto Belt in Kyushu. And finally, this procedure is quite sensitive to small variations of bulk methane contents and trapping pressures.

To illustrate this point, let's consider the water-rich inclusions described in Vrolijk (1987) and Lewis et al. (2000), whose trapping conditions were determined as $T \sim 260-290^{\circ} \mathrm{C}$ and $P \sim 175-300 \mathrm{MPa}$ and $210-250^{\circ} \mathrm{C}$ and 80 $100 \mathrm{MPa}$, respectively. These two examples give an idea of the $P-T$ range of trapping conditions, with a relatively narrow range in temperature and a much larger range in pressure. Using our thermodynamic modeling, we have performed simulations for two inclusions in the system $\mathrm{H}_{2} \mathrm{O}-\mathrm{CH}_{4}$ with the same homogenization temperature $T_{h, \mathrm{aq}}=250^{\circ} \mathrm{C}$ and a gas hydrate melting temperature of $9^{\circ} \mathrm{C}$ and $19^{\circ} \mathrm{C}$, respectively (Fig. 7 and Table 3, inclusions a and b). For $T>T_{\text {hyd }}$, inclusions are constituted of two phases, liquid and vapor, and evolve along an isochore up to $T_{h, \text { aq }}$, where the last bubble of vapor disappears. The two inclusions show a much different isochoric evolution up to $T_{h, \text { aq }}$, with a very large pressure increase for inclusion b, up to $P_{h, \text { aq }}=215$ 
$\mathrm{MPa}$, and a much smaller pressure increase for the inclusion a, up to $P_{h, \mathrm{aq}}=48$ $\mathrm{MPa}$. The strong contrast between the two inclusions is primarily controlled by the very steep slope of the melting gas hydrate curve. A small increment in $T_{\text {hyd }}$ results in a relatively large increase in the inclusion pressure, hence in the density of the methane in the bubble at temperature near ambient conditions: in inclusion a, $P_{\text {hyd }}$ is 3 times larger than in inclusion b (Table 3). As a result, bulk concentration of methane is larger, so that the pressure conditions required to dissolve completely the methane in the water, i.e. $P_{h, \mathrm{aq}}$, are much higher. One can note that the influence of $T_{\text {hyd }}$ on methane concentration is dominant over volumic fraction: Inclusion a is less concentrated in methane though the volumic fraction of methane bubble at ambient $\mathrm{T}$ is larger than inclusion $\mathrm{b}$. The conclusion of this fictive example is that even a small quantity of methane in the inclusion strongly affects the P-V-T properties of the inclusions and raises their isochoric evolution towards high pressure. Therefore, in accretionary prisms (e.g. Vrolijk (1987); Sakaguchi (1999a)) or collision zones (e.g. Mullis (1979)) where dissolved methane is present in water, the estimation of realistic fluid pressure conditions requires to model the fluid in the ternary system $\mathrm{H}_{2} \mathrm{O}-\mathrm{CH}_{4}-\mathrm{NaCl}$. In other words, considering the fluid only in the simplified $\mathrm{H}_{2} \mathrm{O}-\mathrm{NaCl}$ system, whose liquidvapor equilibrium curve runs at very low pressure, leads to underestimating the fluid pressure. Our new approach, which solves this systematic bias and can be used even for very low concentrations in methane, calls for a reappraisal of cases, such as the high-pressure metamorphic stage recorded in the Schistes Lustrés in the Alps (Agard et al., 2000), where a large gap between fluid and mineral pressure was observed. 


\section{Conclusion}

Fluid inclusions contained in rocks deformed in accretionary prisms or in orogenic contexts are the only key to unravel the composition, temperature and pressure of the fluids circulating at depth.

In this work, we have developed a new procedure to study methanebearing aqueous inclusions, commonly found in such geodynamical contexts. The method depends only on microthermometric data, i.e.: the melting temperature of ice, $T_{m \mathrm{i}}$ the melting temperature of gas hydrate, $T_{\text {hyd }}$ and the homogenization temperature, $T_{h, \text { aq }}$. It completely describes the physicochemical properties of the aqueous inclusions (bulk density, composition, phase diagram) and $P-T-$ composition of the circulating fluids. This method is based on an integrated algorithm, involving several state-of-theart thermodynamic models for the $\mathrm{H}_{2} \mathrm{O}-\mathrm{CH}_{4}-\mathrm{NaCl}$ system (solubility and density calculations, phase equilibria modeling) and has a relative precision within $10 \%$.

Modeling methane-bearing aqueous inclusions in the system $\mathrm{H}_{2} \mathrm{O}-\mathrm{CH}_{4}$ $\mathrm{NaCl}$, and not in the simplified $\mathrm{H}_{2} \mathrm{O}-\mathrm{NaCl}$ system, is necessary to recontruct reliable fluid pressures in the depths of accretionary prisms or orogens. Furthermore, in cases where gaseous $\mathrm{CH}_{4}$ inclusions are present in addition to aqueous ones, our method enables to discuss the cogenetic character of the two kinds of inclusions, without invoking any textural argument, often questionable in strongly deformed rocks.

We have applied this new method to the case study of the Hyuga unit from the Shimanto Belt (Japan). After careful microthermometric measurements, we show that aqueous and gaseous inclusions cannot be cogenetic, 
in other words two fluids (a water-rich and a methane-rich one), in disequilibrium, were trapped in the rock at depth. $P-T$ conditions recorded by aqueous inclusions show that after a nearly isothermal exhumation, a very hot geothermal gradient prevailed during the latest stage of the Hyuga unit evolution.

\section{Acknowledgment}

We thanks both reviewers and editor for their detailed and constructive reviews. This work has benefited from the financial support from the ANR programs SLABFLUX (K. Koga), CONGÉ (L. Mercury), INSU program SYSTER and ERC grant RHEOLITH (H. Raimbourg). The thermodynamic modeling has been carried out with a calculation software, which is freely available at http://wwwobs.univ-bpclermont.fr/lmv/pperm/thiery_r/index.php. Raman spectrometry was done at the Thermodynamics Laboratory of the Blaise Pascal University (Clermont-Ferrand).

\section{Appendix A. Detailed equations}

Detailed equations, which are given below, are involved in the formulation of mass balance and volume conservation (equation (1)). For the sake of simplicity, it is understood that these equations are expressed for a fluid inclusion having a volume of $1 \mathrm{~m}^{3}$.

\section{Appendix A.1. State 1: ice melting}

First, when the last piece of ice disappears (state 1 ) at $T_{1}=T_{m \mathrm{i}}$, one has: 
- the number moles of $\mathrm{CH}_{4}$ and $\mathrm{H}_{2} \mathrm{O}$ in the gas:

$$
\left\{\begin{array}{l}
n_{\mathrm{H}_{2} \mathrm{O}, 1}^{G}=\frac{x_{\mathrm{H}_{2} \mathrm{O}, 1}^{G}\left(1-F_{1}^{L_{w}}-F_{1}^{H}\right)}{V_{1}^{G}} \\
n_{\mathrm{CH}_{4}, 1}^{G}=\frac{\left(1-x_{\mathrm{H}_{2} \mathrm{O}, 1}^{G}\right)\left(1-F_{1}^{L_{w}}-F_{1}^{H}\right)}{V_{1}^{G}}
\end{array}\right.
$$

- the number of moles of $\mathrm{CH}_{4}$ and $\mathrm{H}_{2} \mathrm{O}$ in the gas hydrate:

$$
\left\{\begin{array}{l}
n_{\mathrm{H}_{2} \mathrm{O}, 1}^{H}=\frac{F_{1}^{H} \rho_{1}^{H} x_{\mathrm{H}_{2} \mathrm{O}, 1}^{H}}{M_{\mathrm{CH}_{4}} x_{\mathrm{CH}_{4}, 1}^{H}+M_{\mathrm{H}_{2} \mathrm{O}} x_{\mathrm{H}_{2} \mathrm{O}, 1}^{H}} \\
n_{\mathrm{CH}_{4}, 1}^{H}=\frac{F_{1}^{H} \rho_{1}^{H} x_{\mathrm{CH}_{4}, 1}^{H}}{M_{\mathrm{CH}_{4}} x_{\mathrm{CH}_{4}, 1}^{H}+M_{\mathrm{H}_{2} \mathrm{O}} x_{\mathrm{H}_{2} \mathrm{O}, 1}^{H}}
\end{array}\right.
$$

- and the number of moles of $\mathrm{H}_{2} \mathrm{O}, \mathrm{CH}_{4}$ and $\mathrm{NaCl}$ in the aqueous solution:

$$
\left\{\begin{aligned}
n_{\mathrm{H}_{2} \mathrm{O}, 1}^{L_{w}} & =\frac{F_{1}^{L_{w}} \rho_{1}^{L_{w}}}{M_{\mathrm{H}_{2} \mathrm{O}}\left(1+M_{\mathrm{CH}_{4}} m_{\mathrm{CH}_{4}, 1}+M_{\mathrm{NaCl}} m_{\mathrm{NaCl}, 1}\right)} \\
n_{\mathrm{CH}_{4}, 1}^{L_{w}} & =\frac{F_{1}^{L_{w}} \rho_{1}^{L_{w}} m_{\mathrm{CH}_{4}, 1}}{1+M_{\mathrm{CH}_{4}} m_{\mathrm{CH}_{4}, 1}+M_{\mathrm{NaCl}} m_{\mathrm{NaCl}, 1}} \\
n_{\mathrm{NaCl}, 1}^{L_{w}} & =\frac{F_{1}^{L_{w}} \rho_{1}^{L_{w}} m_{\mathrm{NaCl}, 1}}{1+M_{\mathrm{CH}_{4}} m_{\mathrm{CH}_{4}, 1}+M_{\mathrm{NaCl}} m_{\mathrm{NaCl}, 1}}
\end{aligned}\right.
$$

557

The mole numbers of $\mathrm{H}_{2} \mathrm{O}, \mathrm{CH}_{4}$ and $\mathrm{NaCl}$ is then obtained from:

$$
\left\{\begin{array}{l}
n_{\mathrm{CH}_{4}, 1}=n_{\mathrm{CH}_{4}, 1}^{G}+n_{\mathrm{CH}_{4}, 1}^{L_{w}}+n_{\mathrm{CH}_{4}, 1}^{H} \\
n_{\mathrm{H}_{2} \mathrm{O}, 1}=n_{\mathrm{H}_{2} \mathrm{O}, 1}^{G}+n_{\mathrm{H}_{2} \mathrm{O}, 1}^{L_{w}}+n_{\mathrm{H}_{2} \mathrm{O}, 1}^{H} \\
n_{\mathrm{NaCl}, 1}=n_{\mathrm{NaCl}, 1}^{L_{w}}
\end{array}\right.
$$

where different quantities are yielded by equations A.1, A.2 and A.3. 
Appendix A.2. State 2: gas hydrate melting

In the same way, similar equations are derived for state 2 (i.e. when the last nugget of gas hydrate melts at $\left.T_{2}=T_{\text {hyd }}\right)$ :

- the number of moles of $\mathrm{H}_{2} \mathrm{O}$ and $\mathrm{CH}_{4}$ in the gas:

$$
\left\{\begin{array}{l}
n_{\mathrm{H}_{2} \mathrm{O}, 2}^{G}=\frac{x_{\mathrm{H}_{2} \mathrm{O}, 2}^{G}\left(1-F_{2}^{L_{w}}\right)}{V_{2}^{G}} \\
n_{\mathrm{CH}_{4}, 2}^{G}=\frac{x_{\mathrm{CH}_{4}, 2}^{G}\left(1-F_{2}^{L_{w}}\right)}{V_{2}^{G}}
\end{array}\right.
$$

- the number of moles of $\mathrm{H}_{2} \mathrm{O}, \mathrm{CH}_{4}$ and $\mathrm{NaCl}$ in the aqueous phase:

$$
\left\{\begin{aligned}
n_{\mathrm{H}_{2} \mathrm{O}, 2}^{L_{w}} & =\frac{F_{2}^{L_{w}} \rho_{2}^{L_{w}}}{M_{\mathrm{H}_{2} \mathrm{O}}\left(1+M_{\mathrm{CH}_{4}} m_{\mathrm{CH}_{4}, 2}+M_{\mathrm{NaCl}} m_{\mathrm{NaCl}, 2}\right)} \\
n_{\mathrm{CH}_{4}, 2}^{L_{w}} & =\frac{F_{2}^{L_{w}} \rho_{2}^{L_{w}} m_{\mathrm{CH}_{4}, 2}}{1+M_{\mathrm{CH}_{4}} m_{\mathrm{CH}_{4}, 2}+M_{\mathrm{NaCl}} m_{\mathrm{NaCl}, 2}} \\
n_{\mathrm{NaCl}, 2}^{L_{w}} & =\frac{F_{2}^{L_{w}} \rho_{2}^{L_{w}} m_{\mathrm{NaCl}, 2}}{1+M_{\mathrm{CH}_{4}} m_{\mathrm{CH}_{4}, 2}+M_{\mathrm{NaCl}} m_{\mathrm{NaCl}, 2}}
\end{aligned}\right.
$$

- the total number of moles of $\mathrm{H}_{2} \mathrm{O}, \mathrm{CH}_{4}$ and $\mathrm{NaCl}$ in a volume of $1 \mathrm{~m}^{3}$ :

$$
\left\{\begin{array}{l}
n_{\mathrm{H}_{2} \mathrm{O}, 2}=n_{\mathrm{H}_{2} \mathrm{O}, 2}^{G}+n_{\mathrm{H}_{2} \mathrm{O}, 2}^{L_{w}} \\
n_{\mathrm{CH}_{4}, 2}=n_{\mathrm{CH}_{4}, 2}^{G}+n_{\mathrm{CH}_{4}, 2}^{L_{w}} \\
n_{\mathrm{NaCl}, 2}=n_{\mathrm{NaCl}, 2}^{L_{w}}
\end{array}\right.
$$

\section{Appendix A.3. Bulk volume conservation}

And finally, the bulk densities of the fluid inclusion at states 2 and 3, are given respectively by: 


$$
\left\{\begin{array}{l}
\rho_{2}=F_{2}^{L_{w}} \rho_{2}^{L_{w}}+\left(1-F_{2}^{L_{w}}\right) \frac{M_{\mathrm{CH}_{4}} x_{\mathrm{CH}_{4}, 2}^{G}+M_{\mathrm{H}_{2} \mathrm{O}} x_{\mathrm{H}_{2} \mathrm{O}, 2}^{G}}{V_{2}^{G}} \\
\rho_{3}=\rho_{3}^{L_{w}}
\end{array}\right.
$$

569

where densities $\rho_{2}^{L_{w}}$ and $\rho_{3}^{L_{w}}$ of the aqueous solution are obtained from:

$$
\left\{\begin{array}{l}
\rho_{2}^{L_{w}}=\frac{1+M_{\mathrm{CH}_{4}} m_{\mathrm{CH}_{4}, 2}+M_{\mathrm{NaCl}} m_{\mathrm{NaCl}, 2}}{1 / \rho_{2}^{*}+m_{\mathrm{CH}_{4}, 2} v_{\mathrm{CH}_{4}}} \\
\rho_{3}^{L_{w}}=\frac{1+M_{\mathrm{CH}_{4}} m_{\mathrm{CH}_{4}, 3}+M_{\mathrm{NaCl}} m_{\mathrm{NaCl}, 3}}{1 / \rho_{3}^{*}+m_{\mathrm{CH}_{4}, 3} v_{\mathrm{CH}_{4}}}
\end{array}\right.
$$

where $\rho^{*}$ is the density $\left(\mathrm{kg} / \mathrm{m}^{3}\right)$ of the $\mathrm{H}_{2} \mathrm{O}-\mathrm{NaCl}$ aqueous solution for $T$, $P$ and $m_{\mathrm{NaCl}}$ conditions, and $v_{\mathrm{CH}_{4}}$ is the partial molar volume $\left(\mathrm{m}^{3} / \mathrm{mol}\right)$ of dissolved $\mathrm{CH}_{4}$ calculated by a solubility model (e.g. Duan et al., 1992).

\section{References}

Agard, P., Goffé, P., Touret, J.L.R., Vidal, O., 2000. Retrograde mineral and fluid evolution on high-pressure metapelites (Schistes lustrés unit, Western Alps). Contrib. Mineral. Petrol.. 140, 296-315.

Alderton, D., Bevins, R., 1996. P-T conditions in the South Wales Coalfield: evidence from coexisting hydrocarbon and aqueous fluid inclusions. J. Geol. Soc. London 153, 265-275.

Bakker, R., 1997. Clathrates: Computer programs to calculate fluid inclusion $\mathrm{v}-\mathrm{x}$ properties using clathrate melting temperature. Computers \& Geosciences , 1-18.

Bakker, R., Thiéry, R., 1994. Application of chlatrates to fluid inclusion studies, in: De Vivo, B., Frezzotti, M. (Eds.), Fluid inclusions in minerals: methods and applications., Virginia Tech, Blacksburg, USA. pp. 191-208. 
Berman, R., 1991. Thermobarometry using multi-equilibrium calculation: a new technique, with petrological applications. The Canadian Mineralogist $29,833-855$.

Dalla Torre, M., DeCapitani, C., Frey, M., Underwood, M., Mullis, J., Cox, R., 1996. Very low-temperature metamorphism of shales from the Diablo Range, Franciscan Complex, California: New constraints on the exhumation path. GSA. Bull. 108, 578-601.

Duan, Z., Mao, S., 2006. A thermodynamic model for calculating methane solubility, density and gas phase composition of methane-bearing aqueous fluids from 273 to $523 \mathrm{~K}$ and 1 to 2000 bars. Geochim. Cosmochim. Acta 70, 3369-3386.

Duan, Z., Moller, N., Greenberg, J., Weare, J., 1992. The prediction of methane solubility in natural waters to high ionic strength from 0 to $250{ }^{\circ} \mathrm{C}$ and from 0 to 1600 bar. Geochim. Cosmochim. Acta 56, 1451-1460.

Dubessy, J., Thiéry, R., Canals, M., 1992. Modelling of phase equilibria involving mixed gas clathrates: Application to the determination of molar volume of the vapour phase and salinity of the aqueous solution in fluid inclusions. Eur. J. Mineral. 4, 873-884.

El Mekki-Azouzi, M., 2010. Etude expérimentale de l'eau et des solutions aqueuses métastables - implications pour le milieu naturel. Ph.D. thesis. ISTO. Université d'Orléans. Orléans.

Hall, R., 2002. Cenozoic geological and plate tectonic evolution of SE Asia 
and the SW Pacific: Computer-based reconstruction, models and animations. J. Asian Earth Sci. 20, 353-431.

Hara, H., Kimura, K., 2008. Metamorphic cooling history of the Shimanto accretionary complex, Kyushu, southwest Japan: Implications for the timing of out-of-sequence thrusting. Island Arc 17, 546-559.

Hyndman, R., Wang, K., Yamano, M., 1995. Thermal constraints on the seismogenic portion of the southwestern Japan subduction thrust. J. Geophys. Res. 100, 15,373-15,392.

Imai, I., Teraoka, Y., Okumura, K., 1971. Geologic structure and metamorphic zonation of the northeastern part of the Shimanto terrane in Kyushu, Japan. J. Geol. Soc. Jap. 77, 207-220.

Kondo, H., Kimura, G., Masago, H., Ohmori-Ikehara, K., Kitamura, Y., Ikesawa, E., Sakaguchi, A., Yamaguchi, A., Okamoto, S., 2005. Deformation and fluid flow of a major out-of-sequence thrust located at seismogenic depth in an accretionary complex: Nobeoka Thrust in the Shimanto Belt, Kyushu, Japan. Tectonics 24, 1-16.

Letouzey, J., Kimura, M., 1985. Okinawa trough genesis: Structure and evolution of a backarc basin developed in a continent. Mar. Petrol. Geol. $2,111-130$.

Lewis, J., Byrne, T., Pasteris, J., London, D., Morgan VI, G., 2000. Early Tertiary fluid flow and pressure-temperature conditions in the Shimanto accretionary complex of southwest Japan: constraints from fluid inclusions. J. Metamorphic Geol. 18, 319-333. 
Lin, F., Sum, A., Bodnar, R., 2007. Correlation of methane raman $\nu 1$ band position with fluid density and interactions at the molecular level. J. Raman Spectrosc. 38, 1510-1515.

Mao, S., Duan, Z., Zhang, D., Shi, L., Chen, Y., Li, J., 2011. Thermodynamic modeling of binary $\mathrm{CH}_{4}-\mathrm{H}_{2} \mathrm{O}$ fluid inclusions. Geochim. Cosmochim. Ac. $75,5892-5902$.

Mukoyoshi, H., Hirono, T., Hara, H., Sekine, K., Tsuchiya, N., Sakaguchi, A., Soh, W., 2009. Style of fluid flow and deformation in and around an ancient out-of-sequence thrust: An example from the Nobeoka tectonic line ine the Shimanto accretionary complex, southwest Japan. Island Arc $18,333-351$.

Mullis, J., 1979. The system methane-water as a geological thermometer and barometer from the external part of the Central Alps. Bull. Mineral. 102, $526-536$.

Mullis, J., Dubessy, J., Poty, B., O’Neil, J., 1994. Fluid regimes during late stages of a continental collision: Physical, chemical, and stable isotope measurements of fluid inclusions in fissure quartz from a geotraverse in the Central Alps, Switzerland. Geochim. Cosmochim. Ac. 58, 2239-2267.

Munck, J., Skold-Jorgensen, S., Rasmussen, P., 1988. Computation of formation of gas hydrates. Chem. Eng. Sci. 43, 2661-2672.

Murata, A., 1997. Geological map of Miyazaki prefecture (1:200,000).

Oleskevich, D., Hyndman, R., Wang, K., 1999. The updip and downdip limits to great subduction earthquakes: Thermal and structural models 
of Cascadia, south Alaska, SW japan and Chile. J. Geophys. Res. 104, 14,965-14,991.

Peacock, S., 2009. Thermal and metamorphic environment of subduction zone episodic tremor and slip. J. Geophys. Res. 114, 1-9.

Pichavant, M., Ramboz, C., Weisbrod, A., 1982. Fluid immiscibility in natural processes : use and misuse of fluid inclusion data. I. phase equilibria analysis-a theoretical and geometrical approach. Chem. Geol. 37, 1-27.

Pitzer, K., 1973. Thermodynamics of electrolytes. 1: Theoretical basis and general equations. J. Phys. Chem. 77, 268-277.

Potter, R., Brown, D., 1977. The volumetric properties of aqueous sodium chloride solutions from $0{ }^{\circ} \mathrm{C}$ to $500^{\circ} \mathrm{C}$ at pressures up to 2000 bars based on a regression of available data in the literature. preliminary steam tables for $\mathrm{NaCl}$ solutions. Geological Survey Bulletin 1421-C, 1-45.

Powell, R., Holland, T., 1988. An internally consistent dataset with uncertainties and correlations: 3. applications to geobarometry, worked examples and a computer program. Journal of Metamorphic Geology 6, 173-204.

Ramboz, C., 1980. Problèmes posés par la détermination de la composition de fluides carboniques complexes, à l'aide des techniques microthermométriques. C. R. Acad. Sc. Paris, serie D 290, 499-502.

Ramboz, C., Pichavant, M., Weisbrod, A., 1982. Fluid immiscibility in natural processes: Use and misuse of fluid inclusion data. ii. interpretation of fluid inclusion data in terms of immiscibility. Chem. Geol. 37, 29-48. 
Sadofsky, S., Bebout, G.E., 2004. Field and isotopic evidence for fluid mobility in the Franciscan Complex: Forearc paleohydrology to depths of 30 kilometers. Int. Geol. Rev. 46, 1053-1088.

Sakaguchi, A., 1996. High paleogeothermal gradient with ridge subduction beneath the Cretaceous Shimanto accretionary prism, southwest Japan. Geology 24, 795-798.

Sakaguchi, A., 1999a. Thermal maturity in the Shimanto accretionary prism, southwest Japan, with the thermal change of the subducting slab: Fluid inclusion and vitrinite reflectance study. Earth Planet. Sci. Lett. 173, 6174 .

Sakaguchi, A., 1999b. Thermal structure and paleo-heat flow in the Shimanto accretionary prismhimanto accretionary prism. The Island Arc 8, 359-372.

Sakai, T., Nishi, H., Saito, T., Nakaseko, K., Nishimura, A., 1984. Microfossil stratigraphy of the paleogene system in kyushu shimanto belt, in: T., S., Okada, H., Kaiho, K. (Eds.), Biostratigraphy and international correlation of the Paleogene system in Japan, Virginia Tech. pp. 95-112.

Setzmann, U., Wagner, W., 1991. A new equation of state and tables of thermodynamic properties for methane covering the range from the melting line to $625 \mathrm{~K}$ at pressures up to $1000 \mathrm{MPa}$. J. Phys. Chem. Ref. Data 20, 1061-1151.

Soave, G., 1972. Equilibrium constants from a modified Redlich-Kwong equation of state. Chem. Eng. Sci. 27, 1197-1203. 
Spivey, J., McCain, W., North, R., 2004. Estimating density, formation volume factor, compressibility, methane solubility, and viscosity for oilfield brines at temperatures from 0 to $275^{\circ} \mathrm{C}$, pressures to $200 \mathrm{MPa}$, and salinities to 5.7 mole/kg. J. Can. Petrol. Technol 43, 52-60.

Taira, A., Katto, J., Tashiro, M., Okamura, M., Kodama, K., 1988. The Shimanto Belt in Shikoku, Japan-Evolution of Cretaceous to Miocene accretionary prism. Modern Geology 12, 5-46.

Toriumi, M., Teruya, J., 1988. Tectono-metamorphism of the Shimanto Belt. Modern Geology 12, 303-324.

Vrolijk, P., 1987. Tectonically-driven fluid flow in the Kodiak accretionary complex, Alaska. Geology 15, 466-469.

Vrolijk, P., Myers, G., Moore, J., 1988. Warm fluid migration along tectonic melanges in the Kodiak accretionary complex, Alaska. J. Geophys. Res. 93, 10,313-10,324. 


\section{${ }_{713}$ Tables}

Table 1: List of symbols

Table 2: Summary of data for seven representative aqueous inclusions from the Hyuga formation. Input data $\left(T_{m \mathrm{i}}, T_{\text {hyd }}\right.$ and $T_{h, \text { aq }}$ temperatures obtained by microthermometry) permit to characterize the fluid inclusion at different states (in particular, homogenization point and gas hydrate melting point).

Table 3: P-V-T-composition properties of the two fictive inclusions described in 5.3 and in Fig. 7.

\section{$714 \quad$ Figures}

Figure 1: Simplified geological map of the Shimanto Belt on eastern Kyushu, Japan, from Murata (1997); Taira et al. (1988). The Nobeoka Tectonic Line (NTL) constitutes a major tectonic boundary between northern and southern Shimanto. All the samples studied here in microthermometry (red stars) were collected in the highly deformed Hyuga mélange unit, in the footwall of the NTL. Blue dots corresponds to other samples of the same unit, where two-phased, aqueous fluid inclusions are also present. Methane-rich inclusions could be found only near the eastermost extension of the NTL, i.e. near sample Kon-NB26. 
Figure 2: Structures of quartz grains and included fluid inclusions. A: A early-stage vein of quartz, elongated parallel to the foliation, is crosscut by a late-stage vein, visible by its lower density in fluid inclusions. The quartz grains constituting the early-stage veins are elongated parallel to the foliation and show undulose extinction, subgrain formation and grain boundary bulging, while the late-stage vein is virtually undeformed. The latestage vein contains aqueous fluid inclusions, two-phased at ambient temperature. These inclusions are aligned along fracture planes parallel to the vein walls and have themselves an elongated shape parallel to the same direction. B- Undeformed quartz vein showing a variable density of fluid inclusions. Note in picture 2 that a single quartz grain hosts domains of low and high density of inclusions. Fluid inclusions have the same composition and geometry as A. All pictures: optical microscope, A_2 and B_2 with crossed nicols.

Figure 3: Aqueous and gaseous inclusions were the two types of fluid inclusions, which could be easily identified by their very different microthermometric properties and Raman spectra at ambient temperatures. (A) aqueous inclusion, exhibiting a $\mathrm{CH}_{4}$-rich bubble immersed in an aqueous solution; (B) gaseous inclusion composed essentially by a $\mathrm{CH}_{4}$ fluid; (C and D) normalized Raman spectra focused on different parts ( $\mathrm{x}, \mathrm{y}$ or $\mathrm{z}$ ) of the inclusions pictured above. The broad peak of water between 3000 and $3800 \mathrm{~cm}^{-1}$ and the $\nu 1$ sharp peak near $2918 \mathrm{~cm}^{-1}$ of the methane vapour are well visible (Lin et al., 2007).

Figure 4: Distribution of homogenization temperatures $T_{h \text {,aq }}$ of gaseous inclusions in the sample NB25-\#46-zoneB, collected near sample Kon-NB26 in Fig. 1.

Figure 5: Determination procedure of $T_{m \mathrm{i}}$ (a to d) and $T_{\mathrm{hyd}}$ (e to h). We start at low temperatures to nucleate ice (a) or gas hydrate (e). Then, we slowly heat up to some fixed temperature $T_{i}$ (b and $\mathrm{f}$ ) and we freeze rapidly the fluid inclusion ( $\mathrm{c}$ and $\mathrm{g}$ ). If the freezing triggers movement/deformation of the methane vapor bubble, this means that some ice (gas hydrate) was still present at $T_{i}$. Thus, we repeat a new heating/freezing cycle, but with a $T_{i}$ incremented by $0.1^{\circ} \mathrm{C}$, until the freezing does not induce any detectable change of the bubble behaviour ( $\mathrm{d}$ and $\mathrm{h})$. The last $T_{i}$ yields then a good approximation of the disappearance temperature of ice (or gas hydrate). 
Figure 6: $P$-T diagram illustrating the main results obtained from microthermometry and thermodynamic modeling. Black lines are monophasic isochores of gaseous $\mathrm{CH}_{4}$ inclusions, homogenizing mostly between -115 and $-95^{\circ} \mathrm{C}$. Blue lines are isochores calculated for the aqueous inclusions: solid curves represent biphasic liquid-gas isochores, whereas dashed lines are monophasic liquid isochores. Biphasic isochores start from gas hydrate melting points (filled diamonds) and end at homogenization points (empty diamonds). The shaded area represents the peak temperatures of host formation estimated from petrological analyses. The dark arrow symbolizes the earliest stage of isothermal exhumation of the formation, starting from peak metamorphic conditions (empty rectangle, from Toriumi and Teruya (1988)), down to the trapping conditions of aqueous fluid inclusions.

Figure 7: $P-T$ evolution of two fictive inclusions in the system $\mathrm{H}_{2} \mathrm{O}-\mathrm{CH}_{4}$, with the same $T_{h, \text { aq }}=250^{\circ} \mathrm{C}$ but contrasted $T_{\text {hyd }}$, either $9^{\circ} \mathrm{C}$ (a) or $19^{\circ} \mathrm{C}$ (b). Each inclusion is threephased (liquid+vapour+gas hydrate) from $T_{m \mathrm{i}}$ to $T_{\text {hyd }}$, two-phased (liquid+vapour) from $T_{\text {hyd }}$ to $T_{h, \text { aq }}$, then single-phased (vapour) for $T>T_{h, \text { aq }}$. Phase transitions occur along the gas hydrate melting curve and the methane solubility curve corresponding to methane concentration of each inclusion. From the comparison of the two inclusion, one can see that a small increase in gas hydrate melting temperature results in a large increase in pressure at homogenization. 
Supplementary Material: Movies illustrating the cycling procedure to estimate precisely $T_{m \mathrm{i}}$ and $T_{\text {hyd }}$. Each cycle is composed of a slow heating phase, followed by rapid freezing. The presence/absence of a crystal of ice or gas hydrate at the maximum temperature $T_{i}$ of each cycle is detected by the rapid crystal growth upon freezing, which triggers the shrinkage, movement or deformation of the gas bubble. Note that the temperature embedded in the movies needs a correction determined by calibrating the heating/freezing stage.

Movie 1: Cycle $i$ to measure $T_{m \mathrm{i}}$. As $T$ is slowly increased up to $T_{i}$, the bubble expands. Rapid freezing results in bubble shrinkage, showing that ice was still present at $T_{i}$.

Movie 2: Cycle $j$ to measure $T_{m i}$. As $T$ is slowly increased up to $T_{j}$, the bubble expands. Rapid freezing has no effect on the bubble, showing that ice was no longer present at $T_{j}$.

Movie 3: Cycle $i$ to measure $T_{\text {hyd }}$. As $T$ is slowly increased up to $T_{i}$, the bubble moves and deforms. Rapid freezing results in the movement of the bubble towards the bottom of the picture, showing that gas hydrate was still present at $T_{i}$.

Movie 4: Cycle $j$ to measure $T_{\text {hyd }}$. As $T$ is slowly increased up to $T_{j}$, the bubble moves and deforms. Rapid freezing has no effect on the bubble, showing that gas hydrate was no longer present at $T_{j}$. 


\begin{tabular}{|c|c|}
\hline Symbol & Signification \\
\hline subscript $i$ & component $\left(i\right.$ either $\mathrm{H}_{2} \mathrm{O}$ or $\mathrm{CH}_{4}$ or $\left.\mathrm{NaCl}\right)$ \\
\hline \multirow[t]{2}{*}{ superscript $j$} & phase $\left(j=\mathrm{H}\right.$ for gas hydrate; $j=\mathrm{L}_{w}$ for aque- \\
\hline & ous solution; and $j=\mathrm{G}$ for gas) \\
\hline \multirow[t]{3}{*}{ subscript $k$} & state $(k=1$ for ice disappearance point; $k=$ \\
\hline & 2 for gas hydrate disapperance point; $k=3$ \\
\hline & for homogenization point) \\
\hline$n_{i}$ & bulk mole density of component $i\left(\mathrm{~mol} / \mathrm{m}^{3}\right)$ \\
\hline$T$ & temperature \\
\hline$T_{m \mathrm{i}}$ & ice melting temperature \\
\hline$T_{\text {hyd }}$ & gas hydrate melting temperature \\
\hline$T_{h, \text { aq }}$ & $\begin{array}{l}\text { homogenization temperature of aqueous in- } \\
\text { clusions }\end{array}$ \\
\hline$T_{h}$ & homogenization temperature \\
\hline$T_{t}$ & trapping temperature \\
\hline$T_{\max }$ & rock maximum temperature \\
\hline$P$ & pressure \\
\hline$P_{t}$ & trapping pressure \\
\hline$P_{h, \mathrm{aq}}$ & $\begin{array}{l}\text { homogenization pressure of aqueous inclu- } \\
\text { sions }\end{array}$ \\
\hline$P_{g}$ & $\begin{array}{l}\text { pressure of a gaseous isochore along its } \\
\text { monophasic isochore }\end{array}$ \\
\hline$\rho$ & bulk mass density of a fluid inclusion $\left(\mathrm{kg} / \mathrm{m}^{3}\right)$ \\
\hline$\rho_{k}^{j}$ & mass density of phase $j$ at state $k$ \\
\hline$\rho^{*}$ & density of a $\mathrm{H}_{2} \mathrm{O}-\mathrm{NaCl}$ aqueous solution \\
\hline$n_{i}^{j}$ & number of moles of component $i$ in phase $j$ \\
\hline$n_{i, k}^{j}$ & number of moles of component $i$ in phase $j$ \\
\hline
\end{tabular}




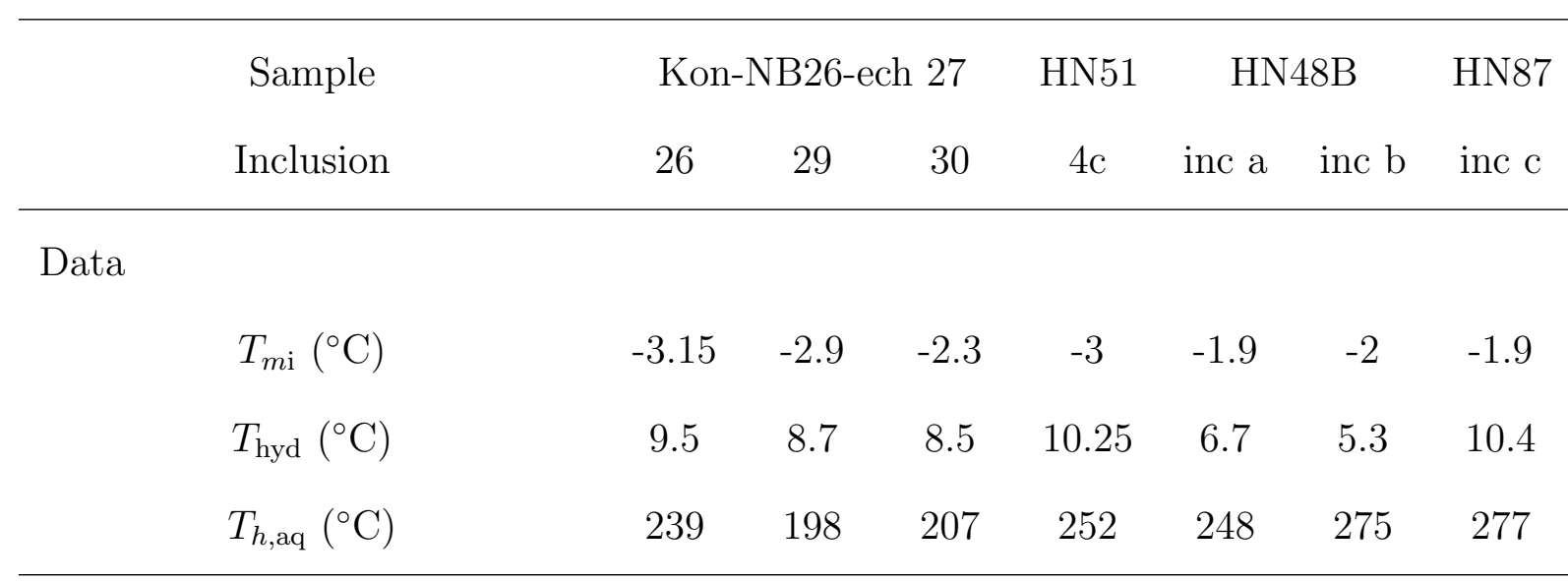

State 3 (homogenization point)

$\begin{array}{cccccccc}P_{h, \text { aq }}(\mathrm{MPa}) & 80.9 & 80.3 & 69.9 & 83.0 & 44.7 & 35.3 & 64.1 \\ \rho_{3}^{L w}\left(\mathrm{~kg} / \mathrm{m}^{3}\right) & 892 & 934 & 914 & 876 & 849 & 809 & 819 \\ m_{\mathrm{CH}_{4}, 3}(\mathrm{~mol} / \mathrm{kg} \mathrm{H} \mathrm{O}) & 0.85 & 0.53 & 0.57 & 1.02 & 0.70 & 0.76 & 1.26 \\ m_{\mathrm{NaCl}, 3}\left(\mathrm{~mol} / \mathrm{kg} \mathrm{H}_{2} \mathrm{O}\right) & 0.83 & 0.77 & 0.60 & 0.77 & 0.49 & 0.52 & 0.46\end{array}$

State 2 (gas hydrate melting)

\begin{tabular}{cccccccc}
$P_{2}(\mathrm{MPa})$ & 8.6 & 7.8 & 7.3 & 9.2 & 5.8 & 5.1 & 8.6 \\
$F_{2}^{G} \%$ & 15 & 10 & 12 & 16 & 18 & 22 & 21 \\
\hline
\end{tabular}

Table 2: 


\begin{tabular}{lccc}
\hline & Sample & & \\
\cline { 1 - 1 } Data & & & \\
& $T_{\text {mi }}\left({ }^{\circ} \mathrm{C}\right)$ & 0 & 0 \\
& $T_{\text {hyd }}\left({ }^{\circ} \mathrm{C}\right)$ & 9 & 19 \\
& $T_{h, \text { aq }}\left({ }^{\circ} \mathrm{C}\right)$ & 250 & 250 \\
& &
\end{tabular}

State 3 (homogenization point)

$\begin{array}{ccc}P_{h, \mathrm{aq}}(\mathrm{MPa}) & 47.6 & 215.6 \\ \rho_{3}^{L w}\left(\mathrm{~kg} / \mathrm{m}^{3}\right) & 824 & 891 \\ m_{\mathrm{CH}_{4}, 3}\left(\mathrm{~mol} / \mathrm{kg} \mathrm{H}{ }_{2} \mathrm{O}\right) & 0.83 & 1.72 \\ m_{\mathrm{NaCl}, 3\left(\mathrm{~mol} / \mathrm{kg} \mathrm{H} \mathrm{H}_{2} \mathrm{O}\right)} & 0 & 0\end{array}$

State 2 (gas hydrate melting)

$\begin{array}{ccc}P_{2}(\mathrm{MPa}) & 6.6 & 20.9 \\ F_{2}^{G} \% & 0.19 & 0.13\end{array}$

Table 3: 


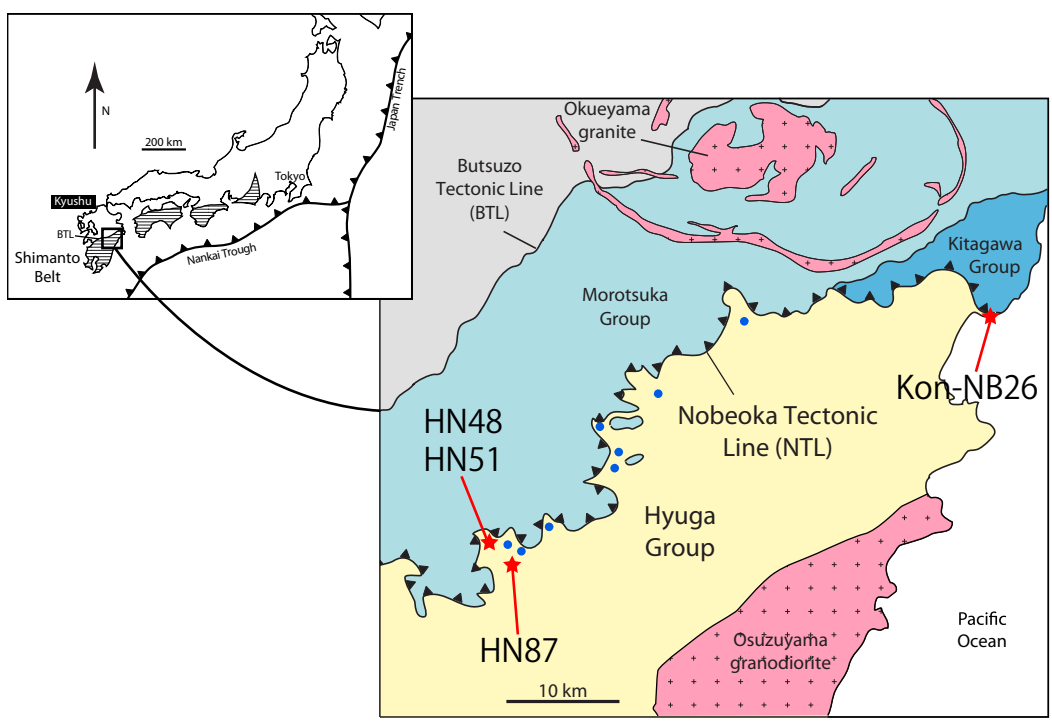




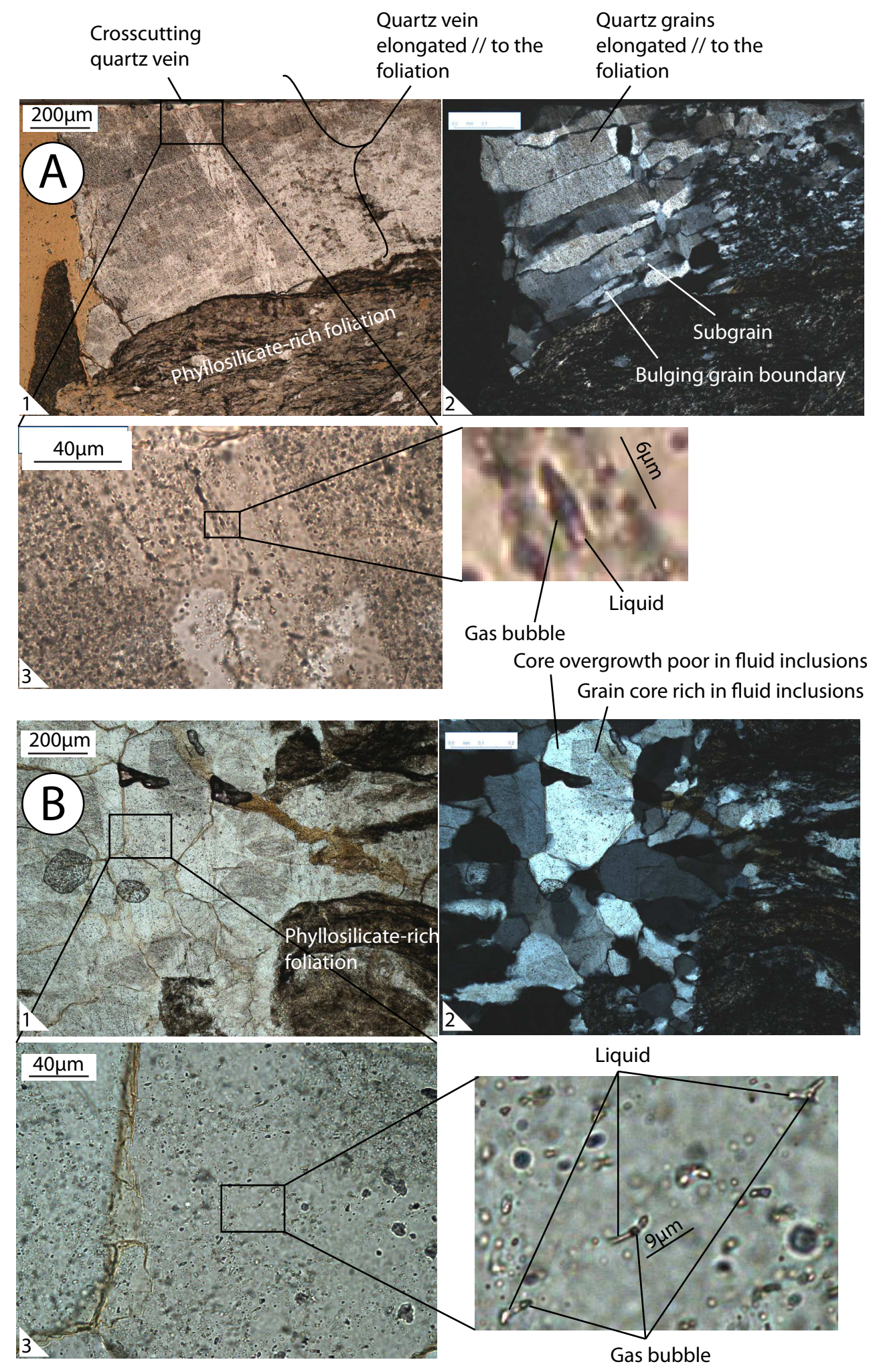



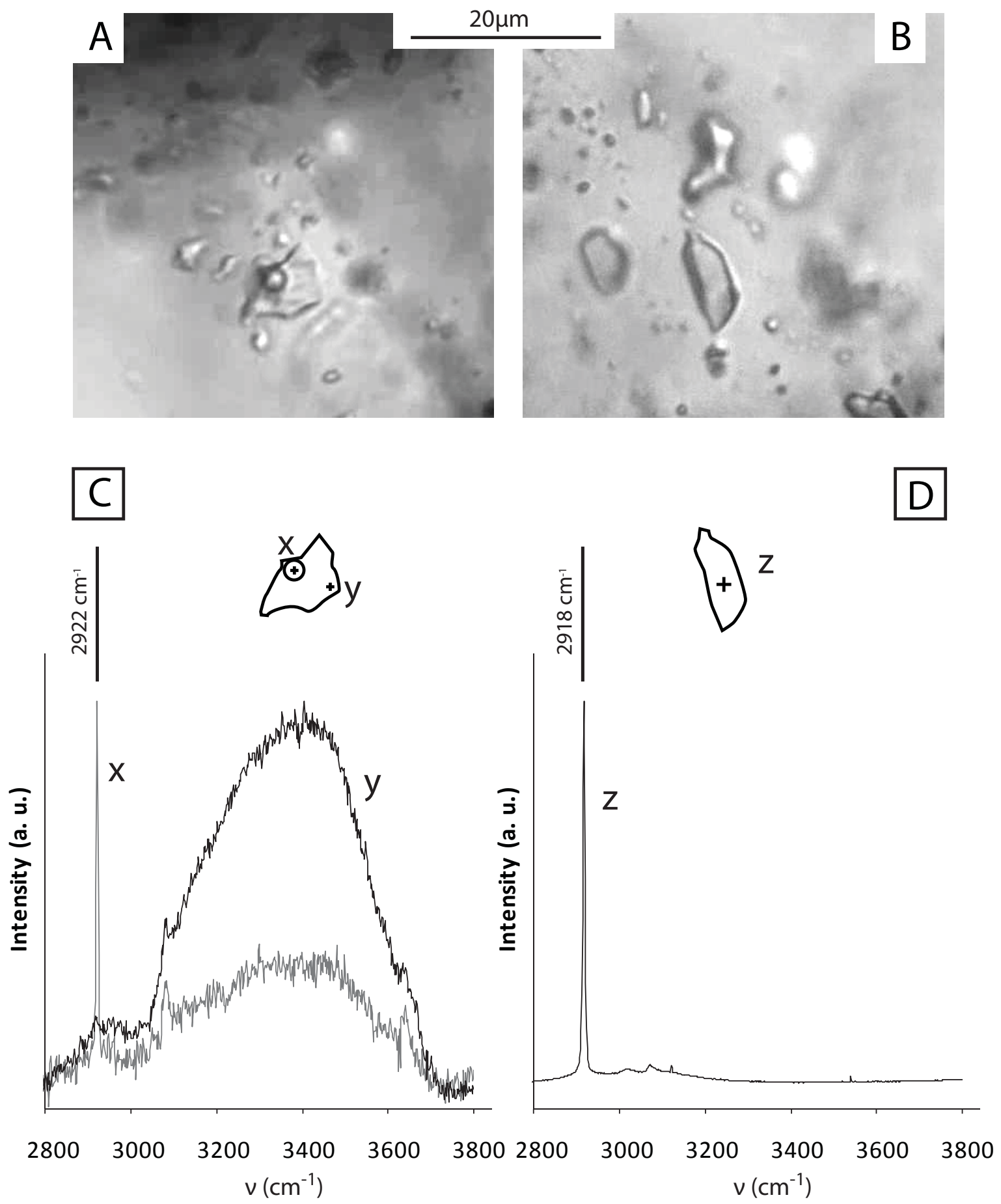

Figure 3: 


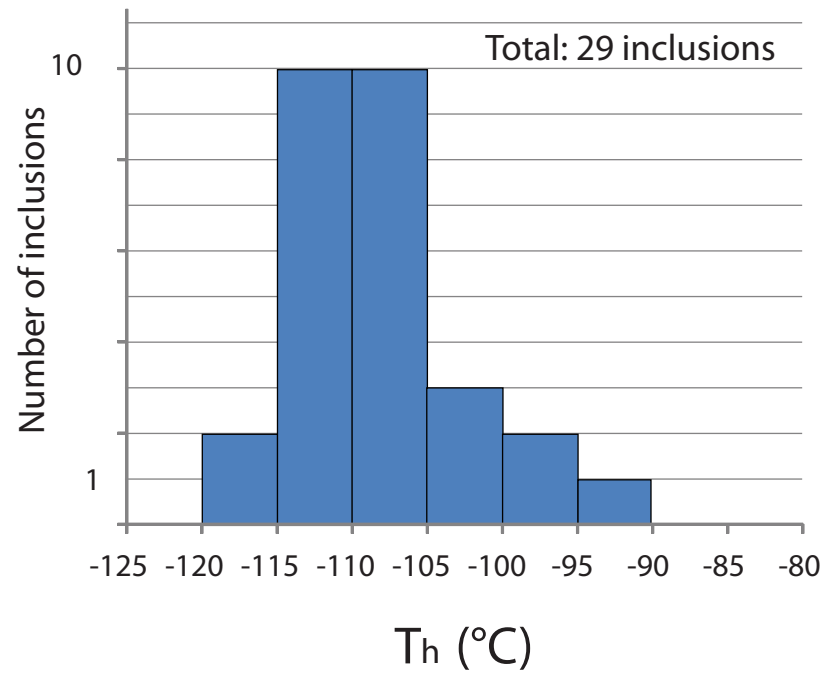


Ice melting

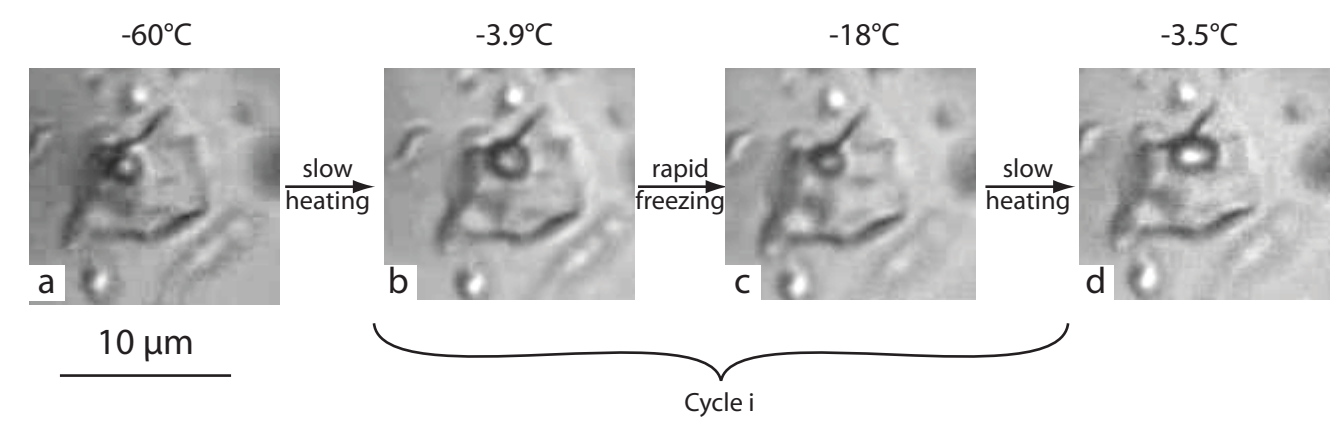

Gas hydrate melting

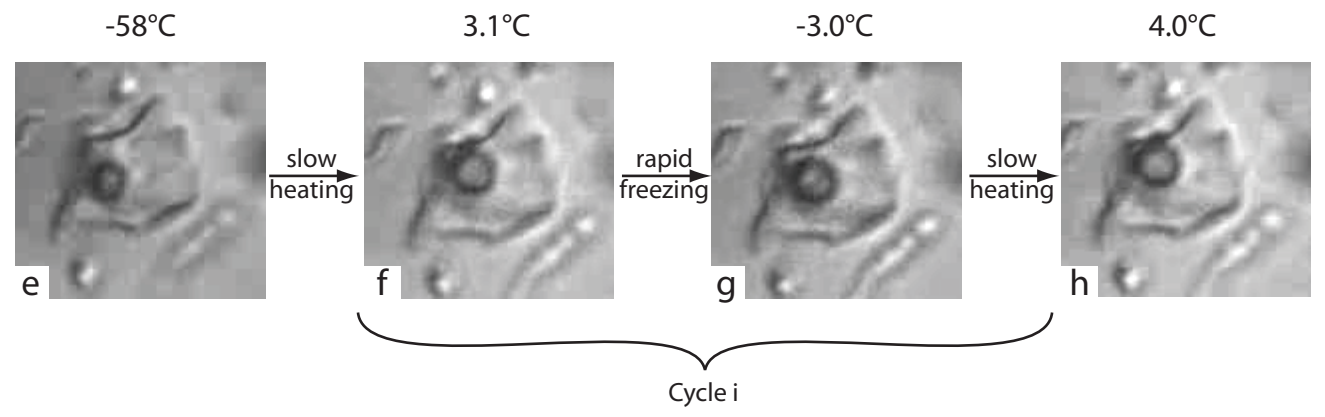




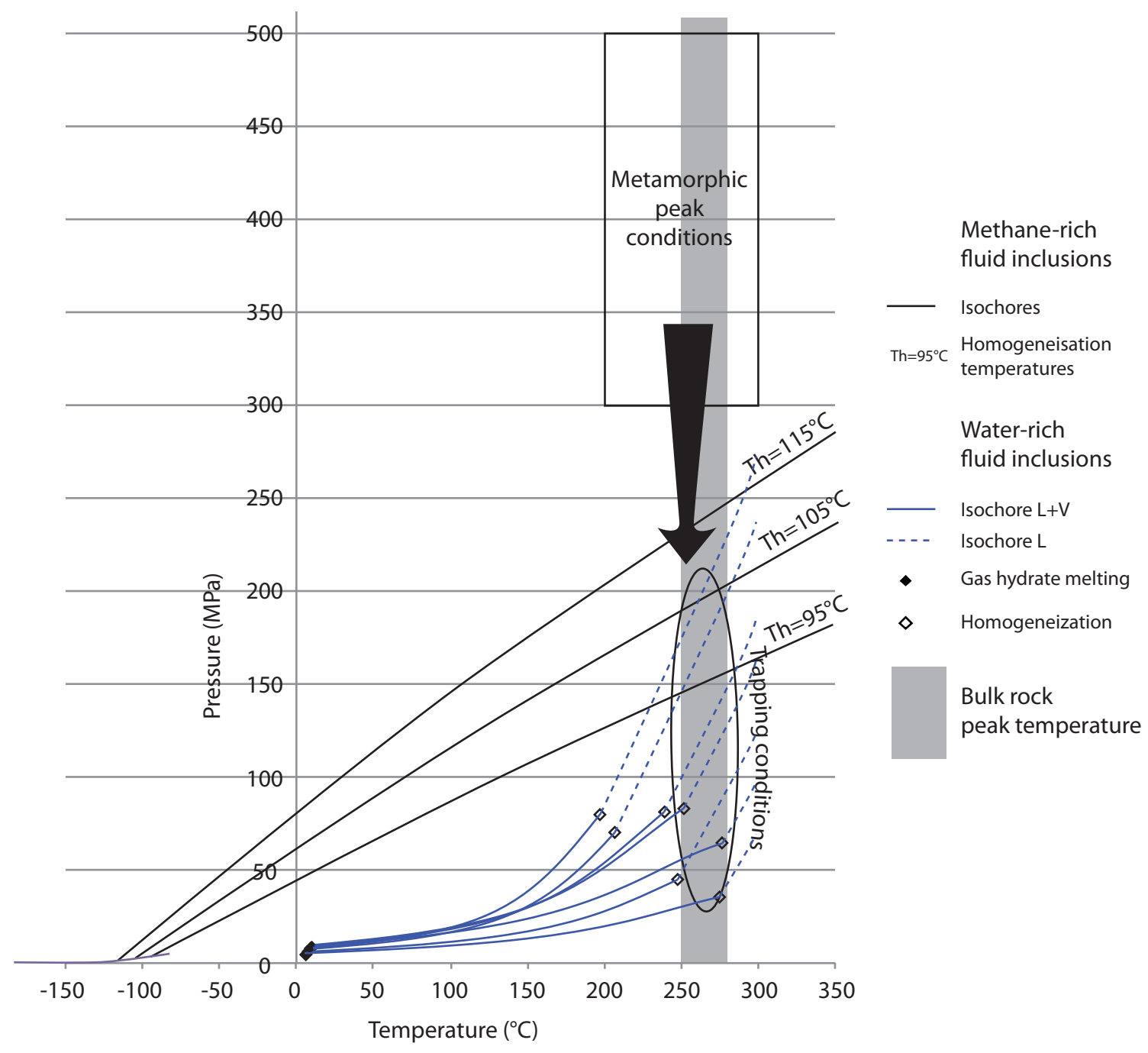




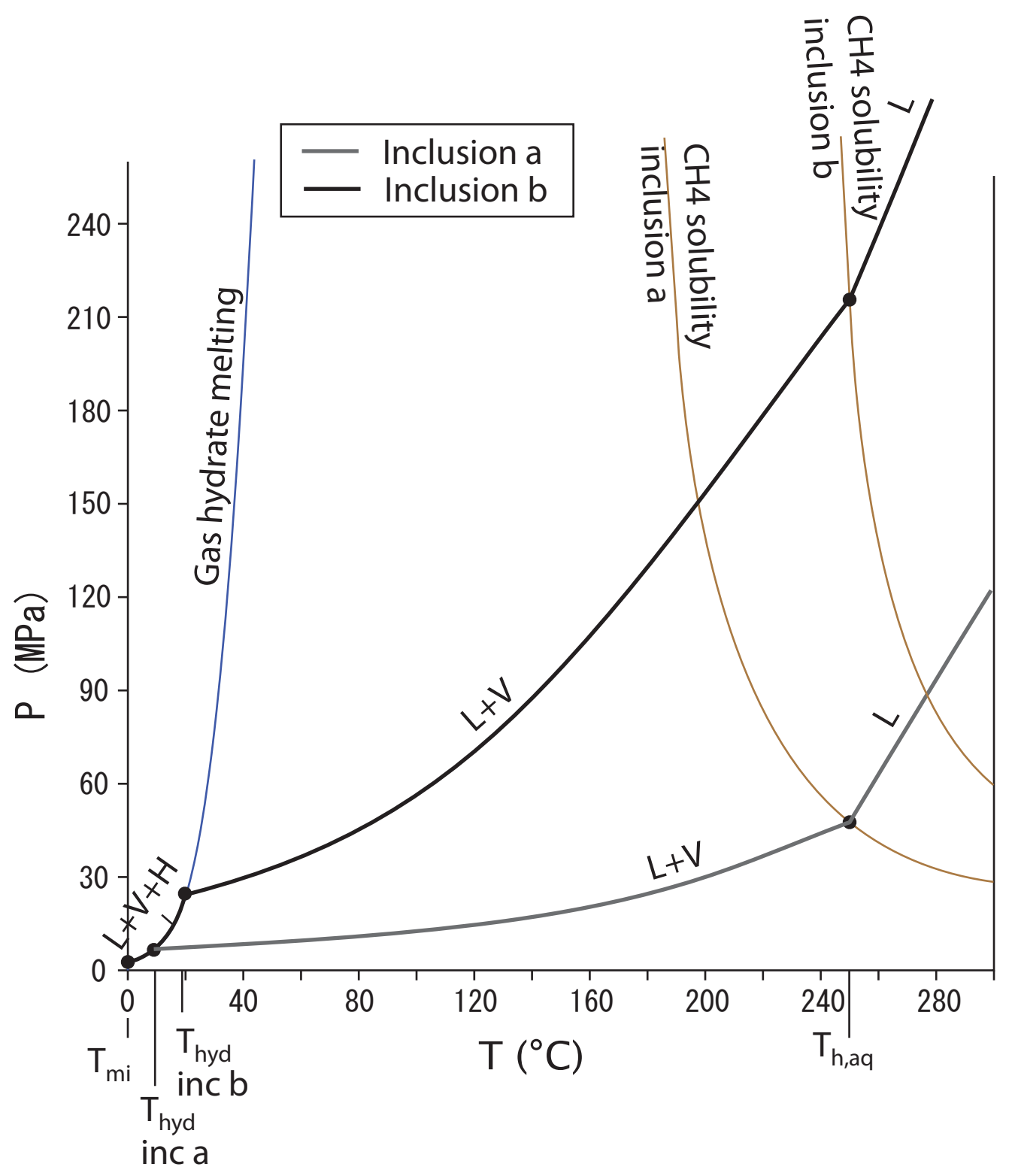

